\title{
Quan es cantava mentre es treballava: tradició oral, codis de conducta i universos simbòlics en el món paperer
}

\author{
Conrad Vilanou (Universitat de Barcelona)
}

\begin{tabular}{l}
\hline Jordi Castellví i Girbau, Cantar i fer paper. Pròleg Jaume Ayats. \\
Vic, Eumo Editorial-Museu de la Ciència i de la Tècnica de \\
Catalunya-Museu Molí Paperer de Capellades, [Col-lecció \\
La Fàbrica, 1], 2018, 157 pàgs.
\end{tabular}

D'entrada podem dir que l'autor és un especialista en antropologia social i cultural, nascut a Capellades el 1964 i professor de la Universitat Autònoma de Barcelona. No cal ni indicar que aquesta vila de l'Anoia és un centre de referència de la indústria paperera del nostre país i a on, a més, es troba el Museu Molí Paperer que és una de les institucions promotores d'aquest llibre. Podem afegir que es tracta d'una obra que posa de manifest els vincles seculars entre el cantar i el treballar, ben coneguts en les ocupacions agrícoles, però també en altres àmbits laborals. Sovint ens vénen a l'oïda -i Joseph Roth se'n va fer ressò en el seu viatge periodístic a Rússia el 1927- els mítics cants dels famosos remers del Volga. «La música es una ayuda mecánica, funciona como una palanca: hay canciones para cuando tiran de un cabo, cuando levantan la carga, cuando la bajan. Las letras son antiguas y primitivas. He oído distintas letras para la misma melodía: hablan de lo dura que es la vida y lo fácil que es la muerte, de mil tipos de tartas, y de las mujeres y el amor. Pero en cuanto la espalda está cargada se interrumpe la canción: entonces todo hombre es una grúa» (Roth, 2020, p. 139-140).

D’aquí que el cant i el treball afaiçonen un binomi que ve de lluny i que, a grans trets, es pot dir que forneix un univers cultural instrumental i mecànic estès arreu.
De fet, aquest univers va més enllà de fronteres, llengües i geografies, i així el cant esdevé un acompanyant del treball que, com indica l'etimologia de la paraula (tripalium), un enginy per a la tortura, sempre implica esforç i cansament. Ara bé, pel que fa al llibre que ens ocupa, aborda les feines que dones i homes desenrotllaven en els molins paperers, sobretot de la conca de I'Anoia, amb l'afluent de la riera de Carme, i el sistema hidrogràfic Mediona-Riudebitlles, que vessen les aigües, sempre magres, al riu principal -l'Anoia- que dóna nom a la comarca igualadina i que, a més, travessa terres de l'Alt Penedès fins aiguabarrejar-se, després de passar per Sant Sadurní i Gelida, amb el Llobregat a l'alçada de Martorell.

Convé tenir en compte que en els darrers temps, la Diputació de Barcelona ha recuperat mediambientalment aquestes petites valls de la riera de Carme i del Mediona, mitjançant una sèrie de camins adjacents a aquests corrents fluvials, quasi bé sempre amb poc cabal, i que permeten contemplar un ric patrimoni preindustrial del país, de molins paperers que sovint es van aixecar en el segle XVIII segurament sobre construccions anteriors. «Almenys seixanta molins van establir en aquesta zona una xarxa importantíssima de producció de paper de qualitat des del segle XVIII i fins ben entrat el segle $X X »(p .12)$. Sumem-hi 
que l'estructura d'aquests molins recordava el sistema polític i social de l'Antic Règim i que, per tant, mantenia un sistema d'explotació d'ascendència feudalista amb una notable presència del paternalisme d'altre temps i que, en línies generals, també es donava a les masoveries de la Catalunya de muntanya. «Entorn de la "Masia" -va escriure mossèn Antoni Griera, en la introducció a La vida a pagès de Salvador Vilarrasa- s'ha creat un petit regne de caràcter patriarcal amb una estructuració perfecta».

Es pot establir, doncs, un cert paral.lelisme entre la masia i el molí paperer, dues institucions que en cert sentit es poden considerar autosuficients. «El molí del segle XVIII i fins al segle XIX era una casa pairal polifuncional que tenia tres vessants: la paperera, la domèstica i l'agrícola. Es podria entendre més aviat com un mas amb funcions de fàbrica» (p. 90). Des d'aquest punt de vista, i sense arribar a ser autàrquics, és prou evident que els molins paperers funcionaven com un món clos en si mateix, fins al punt que les famílies qui habitaven s'emparentaven entre elles, i així Castellví conclou que «l'endogàmia en la indústria era sovint una bona estratègia matrimonial» (p. 92).

Tinguem present que avui molts $d^{\prime}$ aquests molins ja no funcionen i que formen part del passat arqueològic industrial, per bé que alguns continuen actius amb una tecnologia modernitzada. Dit amb altres paraules: el treball manual que acompanyava l'antic procés de l'elaboració del paper forma part d'un passat que, a banda de les fotografies de finals del segle XIX i començament del $x x$, inclou la tradició oral de les cançons i dels balls corresponents, sense oblidar algunes festes com la dels infants, per Sant Nicolau, el 6 de desembre, per bé que el carnestoltes adquiria una significació especial, més encara si es té en compte que durant el període quaresmal quedaven prohibides moltes cançons, per la seva temàtica profana i irreverent. «No hi havia ball, ni espectacles, ni tampoc es podia tocar cap instrument» (p. 98).

Així, doncs, aquest patrimoni arqueològic $\mathrm{i}$ històric no és només material i industrial, o, amb precisió, preindustrial ( $p$. 89), sinó també cultural, «un patrimoni fet de paraules» (p. 9) que, a través de la tradició oral, ja sigui amb històries o bé amb cançons, ha arribat, d'una manera dispersa i fragmentària fins a nosaltres a través de les lletres i de les tonades musicals que es cantaven i de les danses que es ballaven. «La cançó popular trenca el silenci dels patrimonis museístics ordenats, posa un nou so als relats que han domesticat la història econòmica del nostre passat i ens permet desorganitzar el temps i comprendre'l des del conflicte, des de la humanitat» (p. 9). És a dir, gràcies a la cançó podem copsar l'ordre del món laboral, que tenia lloc en un ambient preindustrial que mantenia qualque reminiscència de l'economia feudal, «basada en aliances matrimonials i paternalisme cap als treballadors que no pas a un sistema industrial capitalista amb relacions contractuals Iliures» (p. 89). Si això és així, s'entenen les dificultats que el règim lliberal va tenir per implantar-se en el nostre país, de manera que en el camp de les relacions amb els patrons, i entre els mateixos treballadors, es produïen tensions que trencaven l'equilibri establert.

Naturalment, aquelles tensions trobaven una vàlvula d'escapament i de transgressió en la festa, extrem que es palesava esplèndidament en els dies de carnestoltes amb el dansot que a Capellades es ballava el dijous gras. «Podíem dir que des del punt de vista de l'ús simbòlic, la realitat social està expressada en els relats i viscuda en les cerimònies i les festes» (p. 95). El Ilibre del Jordi Castellví dedica diverses pàgines a comentar el dansot, que depèn del ball rodó, i que s'inscriu en el procés 
festiu carnestoltesc, alhora que es va anar estenent per la conca de l'Anoia i el Mediona-Riudebitlles a mesura que els treballadors es desplaçaven d'un Iloc a un altre. «EI dansot era, doncs, una adaptació del ball rodó agrari al temps i als espais dels molins paperers» (p. 113).

Ben mirat, el ritme cadenciós de la música servia per acompanyar les tasques monòtones i repetitives que les dones i els homes feien en aquests molins, com ho havien fet en les labors agrícoles i en d'altres àmbits com els remers que han esdevingut competicions esportives. Quant a la vida a pagès, Salvador Vilarrasa -en escrits que daten de 1925 i que es refereixen principalment a la muntanya- esmenta que els pagesos cantaven a vegades amb ritme, com quan segaven, però a voltes ho feien sense ritme, per exemple, quan cavaven les trumfes, és a dir, quan sembraven les patates. "Tot cavant també solen cantar però escolleixen cançons que no sien de ritme, perquè havent de treure les herbes no tots piquen igual amb les aixades» (Vilarrasa, 1975, p. 174). Ben diferent, és el que succeïa a l'estiu amb la sega, a càrrec de colles de segadors que anaven d'un lloc a un altre, des de la comarca del Vallès fins a la Cerdanya. A gratcient, les lletres de les cançons dels segadors recorden les que es cantaven als molins paperers, amb el tema de la jove malcasada amb un home vell com assumpte central. Salvador Vilarrasa esmenta un segador de La Pobla de Lillet que indicava que la cançó de la mal cassada («Me n'han casada amb un vell/ que'n té moltes heretats/ la meitat ja són vengudes/ i empenyades l'altra part») s'adeia amb la feina del segar, en acoblar-se la lletra amb les diferents accions de la sega, "de manera que la tonada i l'aire encaixen bé amb aquella feina» (Vilarrasa, 1975, p. 231).

Per això, aquestes cançons no tenien un sentit artístic, sinó instrumental, tal com apunta en el pròleg del llibre Jaume Ayats -director del Museu de la Música de Barcelona- en assenyalar que les «cançons no eren cap objecte, i encara menys cap objecte artístic: eren actes de mediació entre individus i circumstàncies» (p. 6). A banda d'això, aquestes cançons s'aprenien de memòria, amb regles mnemotècniques, i en ser textos oberts, a cada lloc agafaven un aspecte o perfil particular, i així la seva reconstrucció no deixa de ser un xic enrevessada per bé que presenten similituds entre un indret i un altre, encara que amb petites variacions. D'aquí la importància d'aquells que com Joan Amades van recopilar aquestes cançons, que eren cantades per la gent treballadora, lluny de l'academicisme musical de les classes burgeses, que com és ben sabut educaven llurs filles amb l'ensenyament del piano. No debades, es tractava d'una pràctica generalitzada entre les classes acomodades, si bé famílies llibertàries com la de Federico Urales i Soledad Gustavo també van procurar que la seva filla Frederica Montseny -nascuda el 1905- practiqués sense èxit aquest instrument, com ella mateixa va reconèixer en diferents llocs. No obstant això, moltes famílies -i aquí podem portar a collació de nou a la família Montseny- cantaven cançons a llurs infants des del bressol, amb les lletres de poetes populars com ara Ignasi Iglésias, Frederic Mistral, Jacint Verdaguer i Apel.les Mestres.

Abans de continuar, volem fer una precisió atès que la persona que ha escrit aquesta nota bibliogràfica, va conèixer de prop el món paperer durant la infància. Els seus avis havien treballat en molins de la Conca de l'Anoia, a Carme i Gelida. Nogensmenys, de petit, jugava en el molí de Carme, situat a bell mig d'aquest poble que aprofitava el cabal del rec que desviava aigües riera amunt, una vella construcció que probablement provenia de l'època aràbiga i que a més servia de safareig del 
poble, en una època en què a falta d'aigua corrent hom havia d'anar a la font amb càntirs i altres atuells. Gairebé no caldria ni dir que l'aqüífer Carme-Capellades ha estat una font de riquesa i, al seu torn, un condicionant que va afavorir la indústria paperera, tot i que avui lamentablement aquella reserva d'aigua es troba sota mínims per la sobreexplotació.

Per tot plegat, res d'estrany que no ens puguem d'estar de remembrar aquelles bales de paper vell, adquirides als drapaires (ara en diríem paper reciclat) i que havien de servir per generar nova pasta de paper amb altres afegits (draps, guix, etc.). En realitat, es convertien en una mena de tresor que calia escorcollar i on sovint es podien localitzar petites troballes, en publicacions i revistes mig esparracades que servien per despertar la imaginació infantil. És clar que les batalles entre els infants llançant-se grapats de paper malmenat, i altres andròmines, sempre buscant amagatalls darrera de les bales per evitar els impactes de les batusses, constituïen una altra diversió d'aquells infants que veien en el molí paperer una espècie de castell laberíntic, amb diverses escales, finestres i dependències -algunes prohibides per l'accés com el soterrani, on existia la mola que triturava la pasta- però que, en altres ocasions, com ocorria amb els pisos superiors, esdevenien veritables jungles que calia explorar a la recerca de noves aventures.

Però a banda d'aquest món un xic paradisíac i oníric que avui evoquem, tenim ben present quan la nostra àvia -l'Angeleta Llorens- ens explicava històries de la seva joventut, quan treballava en un molí paperer de Gelida i vivia a Carme, d'on era filla de Cal Sastret. Quan érem infants, ens contava que anava a peu a treballar a Gelida des de Carme, una distància d'uns trenta kilòmetres, que feia a peu i pel dret, el dissabte a la tarda de retorn del molí paperer cap a casa, i el dilluns a la matinada abans del trenc d'alba- de tornada per tal de poder arribar a l'hora convinguda per reprendre el treball. Aquest fet no ha de sobtar, si pensem que a pagès es respectava la figura de l'hereu, de manera que les noies eren foragitades de casa des ben menudes amb poc més de set anys per estalviar-se una boca que s'havia d'alimentar. «Moltes treballadores dels molins provenien de pobles allunyats i també de cases de pagès, que enviaven les noies joves i les dones, sobretot, a la indústria per obtenir un complement a l'economia a pagès» (p. 103).

En tot cas, segurament la nostra àvia no feia sola el camí de Carme a Gelida, i a l'inrevés, sinó amb altres dones i, possiblement, amb algun home casat que en devia tenir-ne cura a manera de cap de colla, quelcom similar a la funció que feia el $\mathrm{ca}$ pità en les colles de segadors, també itinerants. Just és de mencionar que l'àvia cantava moltes cançons, algunes litúrgiques, però també estem segurs que devia saberne d'altres que pertanyien a aquell món paperer que va conèixer abans de casar-se el 1923, quan tot just havia complert vint anys. Sigui com sigui, ara -quan ja han passat més de trenta anys del traspàs de l'àvia- lamentem no haver tingut la pensada d'espigolar la lletra d'aquelles cançons que segurament també posseïen un indubtable potencial des d'un punt de vista antropològic i cultural, i que s'haguessin pogut comparar amb altres versions. I tot això, sense comptar els aforismes, les frases fetes i els remeis casolans, alguns dels quals hem rememorat tot llegint aquest llibre. Sortosament, i ben al contrari del que vam deixar de fer en el seu dia, hi ha persones que sí que van saber donar compte i raó d'aquelles cançons i músiques, que marcaven el ritme vital, ja fos laboral o festiu, en un temps religiós o bé 
transgressor com el de carnestoltes. Per consegüent, el batec vital d'aquest món paperer es pot seguir mitjançant aquestes cançons que posen de manifest que els períodes de treball i festa es succeïen al compàs d'un temps que es seguia, sovint, amb el Calendari del pagès, atès que els treballs al molí es combinaven a voltes amb les feines a I'horta o a la vinya (p. 17), en una economia de subsistència en què els patrons deixaven les terres pel conreu amb un pagament en espècie, "a parts», una pel propietari i la resta (tres quartes parts, si mal no recordem) per qui cultivava la terra.

Tampoc fóra difícil demostrar que aquell conjunt de manifestacions fornia una veritable cosmovisió (Weltanschauung) que pot identificar-se amb una mena visió del món que integra les creences religioses, les convencions humanes $\mathrm{i}$ el pas del temps segons el ritme de la natura. Fet i debatut, s'afaiçonava un esguard que aplegava l'esfera del sagrat, la concepció de l'ésser humà com algú lligat a un procés de producció per a la subsistència, i del qual es feia difícil sortir-se'n, i que bategava al compàs de les estacions en un cicle que era viscut a través de les festes del calendari i, nogensmenys, de les llunes que guiaven les tasques agrícoles, sobretot de la sembra.

Igualment, és necessari tenir en compte que a més de donar un sentit al món aquestes cançons serveixen per informar-nos sobre les condicions de vida, «de l'experiència quotidiana humana i de les desigualtats dels treballadors» (p. 16). Tot això fornia una arquitectònica social que servia per orientar la vida de persones que tenien una escolaritat ben minsa i on el nombre d'analfabets era substancial. S'ha dit que gràcies als seminaristes dels bisbats de Vic «gairebé tots els pagesos de la Muntanya sabien llegir i escriure» (Vilarrasa, 1975, p. 7), però això no passava en les zones de l'Anoia, com a mínim tal i com les recordem. A tot estirar, aquelles dones -recordo ben bé a la meva àvia i a les seves germanes i cunyades- posseïen unes mínimes nocions de lectoescriptura i poca cosa més, i quan jo mateix vaig haver d'omplir en alguna ocasió els papers del cens, ambdós avis em van repetir que posés que l'àvia sabia llegir i escriure, cosa que feia amb dificultat, per bé que s'esmerçava molt en la signatura d'aquella documentació franquista que a més venia tota en castellà.

Al fons, una de les intencions del professor Castellví rau en palesar la dinàmica que es va produir entre aquell univers paperer que representava un món d'ahir i el mite de progrés accelerat de la modernitat, fins l'extrem que a redós dels vents romàntics tot aquell complex que «estructura i legitimava un ordre social» es va «transformar en folklore i en patrimoni» $i$, així, es «va crear el mite de la tradició» que Castellví defineix de la següent manera. «El mite del passat rural com una arcàdia rousseauniana, amb gent de cor senzill i bona fe que mantenien feines, creences, festes, cançons, jocs i costums sorgits directament del geni del país» (p. 19). És per això, també, que els folkloristes del segle XIX i primers compassos del segle $\mathrm{XX}$, majoritàriament conservadors i catòlics, van sortir a recollir, ordenar i classificar tot tipus de materials, entre els que destaquen les cançons i els balls, encara que com bé assenyala Castellví «es va crear un mite col-leccionant una ficció: coses aparentment pures, senzilles i immutables» (p. 20). De fet, llibres com La vida a pagès de Salvador Vilarrasa i Vall, fill de l'alta muntanya, confirmen aquest punt, i així no estranya que els propietaris rurals veiessin en la pagesia una «gran do de Déu l'haver nascut a la Pagesia», paraules que introdueixen aquell llibre i que posen de manifest que abans de baixar a la Plana de Vic, molts d'aquells 
pagesos s'estaven al Lluçanès, al Berguedà o al Ripollès.

De retop, Castellví afegeix que així es van generar cançoners populars però després d'una depuració o expurgació, atès que van ser rebutjades «aquelles cançons que no creien possible que fossin veritablement del poble», com reconeix que va fer el mateix Joan Amades (p. 21). Establerta així aquesta qüestió, resulta lògic que es considerés que del poble i del seu esperit (Volksgeist) no podia emergir res indecorós i, encara menys, pecaminós, perquè calia mantenir l'ideal que la gent rural era pura en no haver estat contaminada pels destrets de la societat industrial que havia pervertit el gènere humà, una idea que Àngel Guimerà va reflectir a Terra baixa (1896), que els treballadors d'aquells molins paperers representaven en les obres de teatre d'aficionats. No debades, el nostre avi, Antoni Vilanou, nascut el 1898 i de sobrenom Ton Manó, que havia treballat en diferents molins de la riera de Carme, de ben gran encara recitava passatges sencers del Manelic, el personatge que exemplifica la puresa rural i que estima la Marta sense malignitat, enfront de la cobdícia i perversitat del Sebastià, el que viu a ciutat, a la terra baixa. Al capdavall, i tal com Castellví apunta, l'exaltació de la tradició i del progrés, dos conceptes ben arrelats en la història del pensament del segle $\mathrm{XIX}$, i que es troben per exemple al darrera de les guerres carlines, afaiçonen "dues mirades, dues direccions per explicar-nos el món» (p. 23). En suma, tot funciona a través d'un sistema dicotòmic, que simplifica les coses i que, al seu torn, posseeix una gran càrrega didàctica, en el sentit que marca dos camins, el del bé i el del mal, amb la qual cosa adquireix característiques pedagògiques que condueixen i dirigeixen la vida de les persones, fins i tot illetrades, per la senzillesa expositiva d'aquestes dues possibilitats.
D’aquí la importància, del cançoner que va recollir una noia, Montserrat Cardús (Lavit, 1887-Rubí, 1918), «minyona i paperera a Lavit i més endavant teixidora i cosidora de seda a Esparreguera i Rubí» (p. 26). Tal com assenyala Jaume Ayats en el pròleg,

la gran majoria de les cançons van ser apunta-
des per una noia jove, mentre treballava al
molí, en una mena d'autocançoner o de recull
propi -d'allò que li agradava cantar i d'allò que
sentia al seu voltant-, que fan el document ex-
cepcionalment interessant: que una treballa-
dora documenti el cant dels molins ella ma-
teixa és un cas extraordinari, i digne d'ocupar
un lloc molt singular en la història de les recer-
ques (p. 7).

Convé consignar que la jove Montserrat Cardús ja reunia cançons a l'edat de setze anys i aviat es va convertir -sempre segons Castellví- en una informant de folkloristes com ara Adelaida Ferré i Gomis, deixebla de Rossend Serra i Pagès. No debades, podem afegir que Montserrat Cardús va morir jove, víctima de la pandèmia de la grip de 1918, circumstància que no deixa de ser paradoxal perquè quan escrivim aquestes notes, a la primavera de 2020, ens trobem en ple confinament pel Covid-19. Després de les seves tasques quotidianes, amb poca llum, Montserrat Cardús transcrivia un arsenal de materials, a saber, «cançons, rondalles, costums, remeis i proverbis que anotava i ordenava de memòria a les nits» (p. 27). Amb aquest rerefons, Castellví indica que les cançons van ser aplegades entre 1905 i 1906, però sobretot les lletres, ja que les tonades canviaven d'un lloc a un altre, perquè com hem vist amb la nostra àvia la «gent anava i venia» (p. 28). Sense dubte que vivim en un món emparaulat, en mig de llengües (català, castellà, francès, etc.), però també, i, sobretot, entre llenguatges, verbal, icònic, simbòlic, etc. «Res no té existència fora del sistema del llenguatge, verbal o d'altres símbols, com els gests, les accions consue- 
tudinàries o rituals...» (p. 36). Per tant, l'emparaulament del món no només s'articula a través de la línia culta dels conceptes, discursos i narratives (tal com ha indicat manta vegades el professor Octavi Fullat i, igualment, el malaguanyat Lluis Duch, un dels referents intel-lectuals de l'autor del llibre que comentem), sinó que també es donen altres emparaulaments, com el que es reflecteix en el món dels molins paperers en què d'una manera popular les cançons explicaven històries que també donaven sentit al món.

Certament, aquí rau un dels mèrits del llibre que ens ocupa, en recuperar aquest autocançoner de la Montserrat Cardús que així esdevé una font primària de coneixement, ultra les que van reunir altres folkloristes com Aureli Capmany i Joan Amades. D'aquesta manera, Castellví procedeix a fer una tasca interpretativa o, si es vol, hermenèutica en el sentit d'extreure'n un seguit de consideracions i valoracions sobre la vida en aquell cosmos paperer que també formava part del món d'ahir. Però si Stefan Zweig es va fixar en el món de la burgesia de l'Europa central (Mitteleuropa), Castellví posa el focus en la gent humil de la indústria paperera d'una zona molt concreta de la geografia catalana, que té Capellades com a centre neuràlgic. Pel que fa al nostre interès, en tractar-se d'una revista pedagògica, deixem en un segon terme els aspectes musicològics per atendre els punts que tenen a veure amb el sistema de transmissió de valors que es donava entre les persones que feien anar la indústria paperera que sovint portaven una vida itinerant, atès que anaven a buscar la feina als molins on llogaven treballadors. Fins i tot, els infants s'incorporaven a aquelles feines, els nois com a gats, per poder circular per petits espais, amb el consegüent perill, cosa vetada als adults per les seves dimensions físiques. Una infància que no va conèixer pel general l'escolarització, entre treballs agrícoles o als molins, i que la seva formació provenia d'aquella tradició oral que, a través de les cançons, transmetien codis de conducta i universos simbòlics. No debades, Jordi Castellví afirma que «la cançó, juntament amb altres productes poètics populars, serveix com a sistema autodisciplinari, ja que és un instrument molt eficaç per controlar les conductes» (p. 41), amb la qual cosa, d'acord amb Michel Foucault, es poden inscriure en les instàncies i dispositius del poder, per tal de mantenir l'statu quo imposat per la classe dominant que sotmetia les persones que treballaven en els molins paperers a estructures rígides.

És obvi que un llibre com el que tenim a les mans permet moltes lectures, antropològiques, musicològiques i, fins i tot, pedagògiques. De fet, el lector no només trobarà cançons, sinó també fotografies que donen informació sobre els vestits, les eines i estris emprats en les feines dels molins paperers, la posició social dels treballadors segons el lloc que ocupen en les imatges, sense bandejar la separació de sexes, «amb barreres físiques, però també simbòliques i verbals» (p. 45). De fet, segons Castellví, hi havia espais i cançons per a cada sexe, amb les consegüents enredades pels aprenents que patien veritables rituals d'iniciació per part dels més grans, «cosa que es devia donar en els molins més i tot que en altres ocupacions a causa del sistema d'aprenentatge tradicional de l'ofici de paperer que es basava en el mosso» ( $p$. 48). Cal tenir en compte, doncs, que sovint s'aplicaven sobre els infants bromes pesades que «els aprenents havien de suportar, a més d'un treball molt dur» (p. 85).

En aquest context, l'amor romàntic ocupa un lloc significatiu atès que va sorgir en un ambient industrial, en què la dona assumeix la funció de reproduir la mà d'obra, «present i futura, a preu zero 
per al sistema» (p. 53). Quan es va trencar l'ordre feudal dels casaments per interessos i conveniències patrimonials, va sorgir l'amor romàntic, tot coincidint amb el pas del món agrari al industrial, preludi del progrés lloat per la filosofia positivista amb la seva exaltació de l'estètica del ferro. No és pas debades que en un món obrer, sense riquesa patrimonial, només quedava l'amor que el romanticisme va exaltar com una nova lògica social, que va ser jutjada críticament per diferents escriptors des de Flaubert a Tolstoi. Malgrat això, en el món dels molins paperers les coses eren més senzilles, de manera que temes com l'amor, el prometatge, el matrimoni sovint dissortat, la malcasada amb un home gran, els enganys en les relacions conjugals, els abusos de l'estament eclesiàstic, la mort, etc. es succeeixen en aquestes cançons que comporten implícitament uns codis de conducta i un conjunt simbòlic, més encara si es té en compte que «la simplificació i la reducció per donar sentit al món és inevitable» (p. 15).

Perquè a dir veritat, tot aquest ventall de temes queden reflectits en les lletres de les cançons que en ocasions tenen una dimensió d'advertència, a manera de saviesa popular o ensenyament paremiològic. I això sempre en una direcció oberta, perquè a banda que la tradició oral mai és fixa ni tancada, el nomadisme dels treballadors feia que les cançons presentessin variants, sense oblidar que tenien «una capacitat formidable d'explicar mons significatius i, alhora, crear-ne de nous» (p. 64). A més, i tal com hem indicat més amunt, les lletres d'aquestes cançons oferien regles mnemotècniques, ja presents en els cants homèrics, per facilitar-ne la reproducció, la qual cosa «limitava el desenllaç improvisat, pel tema i per la rima» (p. 65). Parem atenció en què l'ésser humà durant molts segles ha viscut segons els paràmetres de la tradició oral, que només l'alfabetització aconseguida - $\mathrm{i}$ no sense penúries- ben entrar el segle $x x$ ha arraconat a un segon terme en la cultura occidental. No per atzar, Plató en el Fedre, tot fent-se ressò del mite egipci de Teüt, va condemnar l'escriptura.

Això establert, hi ha alguns aspectes del llibre que tampoc volem deixar passar per alt. És per això que ens hem de referir a les cançons narratives, cantades per homes o bé per dones, que confirmen que vivim en un món emparaulat que dona sentit al significat de les coses. «En definitiva, la cançó llarga aconsegueix implicar els participants en una història davant la qual no es poden quedar indiferents» (p. 73). Endemés, aquestes cançons servien de control social, sobretot de les dones, en regular de manera inconscient, però ben palesament $\mathrm{i}$ inequívocament, la seva conducta. «Es tractava de fer complir una sèrie de normes que tothom sabia $\mathrm{i}$ es tenien com a naturals» (p. 83). Ara bé, no hi ha dubte que aquestes cançons portaven un valor afegit simbòlic, atès que «la realitat social està expressada en els relats i viscuda en les cerimònies i les festes» (p. 95).

Comptat i debatut, Castellví -tot seguint Blacking (1999)- constata que en aquella època tothom cantava, d'una manera coral, situació que ha canviat, en el sentit que la cultura burgesa va potenciar I'erecció de teatres, orquestres i temporades de concerts, sense oblidar l'òpera. No per casualitat, Goethe dirigia el teatre de Weimar. A redós d'aquest procés, que va restringir el cant a una classe especialment preparada, es va promoure el plaer de l'escolta, mentre una minoria interpretava amb els instruments, en un elaboració cada vegada més perfeccionista que, a més, va comptar a partir de la dècada dels anys vint amb l'impacte de la ràdio, amb retransmissions de concerts i l'arribada de nous ritmes com el jazz. En fi, la música 
que era una cosa arrelada a les classes populars, com els orfeons i els cors de Clavé posen de relleu, va esdevenir un bé cultural més restrictiu, propi d'una minoria, encara que músics com el mestre Pau Casals van procurar estendre la música orquestral a tothom a través de sessions musicals populars, adreçades a la gent treballadora. Però sembla que haguem fugit d'estudi, i hàgim oblidat el Ilibre del professor Jordi Castellví que constitueix un bon recurs per conèixer, d'una banda, la inserció de la música en el món de la cultura i de l'antropologia, amb referències a l'educació popular, i per altra, aprofundir en aquestes cançons de la indústria paperera que tot cantant transmetia uns codis o pautes de conducta i un univers simbòlic que formen part d'un passat fonedís. A tot estirar, aquest patrimoni perviu -si més no, parcialment- en la ment d'aquells, com és el nostre cas, que vam tenir la sort de conèixer, ni que fos lúdicament i familiar, aquell món paperer que avui diríem que s'inscrivia en un model d'economia circular, perquè de les deixalles del paper vell, malmès i espellifat, sortien noves raimes de paper, cadascuna de les quals estava formada per cinc-cents fulls de paper que equivalien a vint mans o cent quaderns. Tot un món, el d'aquelles mesures, que amb les càrregues de vi, les quarteres de blat i els quintars de patates, també forma part del món ahir, que aquest llibre ens ha fet reviure de manera evocadora i precisa, alhora que ens dóna una visió de la trajectòria de la nostra societat post-industrial (Daniel Bell) que ha deixat enrere aquell sistema preindustrial del segle xviii, i industrial del xix i començament del $x x$ de la indústria paperera on es treballava tot cantant, com en altres feines. Ni més, ni menys.

\section{Referències}

Bell, D. (1976) El advenimiento de la sociedad post-industrial: un intento de prognosis social. Madrid, Alianza.

Blacking, J. (1999) Fins a quin punt l'home és músic. Vic, Eumo.

Fullat, O. (2005) Valores y narrativa. Axiología educativa de Occidente. Barcelona, Publicacions i Edicions de la Universitat de Barcelona.

Roth, J. (2020) Años de hotel. Postales de la Europa de entreguerras. Barcelona, Acantilado.

Vilarrasa i Vall, S. (1975) La vida a pagès. Introducció d'Antoni Griera. Ripoll, Impremta Maideu. 